\title{
Prevalence and Characteristics of Sexual Hookups Among First- Semester Female College Students
}

\author{
Robyn L. Fielder, M.S. and Michael P. Carey, Ph.D. \\ Center for Health and Behavior, Syracuse University
}

\begin{abstract}
First-semester female college students $(N=118)$ completed (a) surveys to estimate the prevalence of sexual hookups and (b) event-level assessments to clarify the behavioral characteristics of their most recent hookup. Hookups involving oral, vaginal, or anal sex were reported by $51 \%$ prior to college, $36 \%$ during their first semester, and $60 \%$ by the end of their first semester. Event-level analyses revealed that hookups were more likely to involve friends (47\%) or acquaintances (23\%) rather than strangers $(14 \%)$; alcohol use (median $=3$ drinks) preceded $64 \%$ of hookups. Condoms were used during $69 \%$ of vaginal sex hookups.
\end{abstract}

\section{Keywords}

hookup; sexual behavior; alcohol; college students; adolescents

Popular books, such as Unhooked (Stepp, 2007) and Hooking Up (Bogle, 2008), describe a pervasive sexual "hookup" culture among high school and college students. These influential accounts draw upon anecdotal evidence to suggest that traditional dating has been replaced by "hooking up." Hookups are sexual interactions between partners who are not in a romantic relationship (Bogle, 2008). Although scholarly research on the hookup phenomenon has begun to emerge, two fundamental questions remain unanswered: How common are hookups? and What characterizes a hookup? The current research addressed these two important questions.

Prevalence-Confidence in prior estimates of the prevalence of hookups is undermined by the use of imprecise definitions of hookup partnerships and behaviors. The type of relationship has been defined inconsistently, with some authors limiting hookups to "one-night stands" (e.g., Eshbaugh \& Gute, 2008; Penhollow, Young, \& Bailey, 2007) and others stipulating only that the partners not be in a romantic relationship (e.g., Garcia \& Reiber, 2008; Owen, Rhoades, Stanley, \& Fincham, in press). Hookup behaviors have also not been defined precisely (e.g., Lambert, Kahn, \& Apple, 2003; Paul, McManus, \& Hayes, 2000), allowing students to define the term idiosyncratically. Using investigator-generated definitions for hookup does not resolve this methodological challenge because students may disregard this definition and answer questions with their own personal understanding of the term. Therefore, to address these concerns in the current study, we did not use the term hookup when assessing prevalence. Instead, we defined a casual partner in such a manner that captured the essence of hooking up (cf. Bogle, 2008; Paul \& Hayes, 2002) and asked about specific sexual behaviors in such partnerships.

Address correspondence to: Michael P. Carey, Ph.D., Dean's Professor of the Sciences and Director, Center for Health and Behavior, 430 Huntington Hall, Syracuse University, Syracuse, NY 13244-2340, Tel.: +1 315443 2755, Fax: +1 315443 4123, mpcarey@ syr.edu. 
Characterizing hookups-Young people use the term "hookup" to refer to a wide range of intimate interactions between partners (Paul \& Hayes, 2002). The ambiguity inherent in the term affords privacy but obscures a precise understanding of the phenomenon. Therefore, the other purpose of this study was to explore the defining characteristics of hookups as reported by college women. ${ }^{1}$ Toward this end, we used an event-level approach to elicit information about participants' most recent hookup (cf. Weinhardt \& Carey, 2000); this approach reduces memory burden, avoids averaging across experiences, and provides precise information about hookups.

We investigated eight dimensions of hookups that have either not been well-researched or have been subject to conflicting results: (1) partner type (e.g., friends, strangers), (2) duration of the relationship ("one-night stand" vs. multiple events), (3) alcohol and drug use, (4) the motivation for hookups (e.g., sexual desire, peer pressure), (5) the specific sexual behaviors that occurred, (6) condom use, (7) emotional reactions, and (8) differences between romantic relationships and hookups.

\section{Methods}

\section{Participants}

Participants were 118 first-semester female college students recruited from an introductory psychology course for a study on "health behaviors and relationships." On average, participants were 18 years old $(S D=0.2)$. Ethnic background was $71 \%$ Caucasian, $12 \%$ Asian, $10 \%$

Hispanic, 5\% African American, and 2\% other. At study entry, most participants (61\%) were single, $20 \%$ were in a committed relationship, $18 \%$ were dating one person, and $1 \%$ were dating more than one person. At study entry, participants also reported an average of 2.4 lifetime oral sex partners $(S D=3.2$, median $=2)$, and 1.5 lifetime vaginal sex partners $(S D=1.9$, median $=1$ ). All participants lived in on-campus residence halls during their first semester and were not yet eligible to join sororities.

\section{Procedures}

All procedures were approved by the Institutional Review Board. After providing written informed consent, students completed two surveys. The initial survey (T1) occurred at the beginning of the semester in September 2007, and the second survey (T2) was completed at the end of the semester in late November or early December $2007(n=109)$. The surveys were linked using a non-traceable code. Upon completion, participants received course credit.

\section{Survey Materials}

In the first section of the survey, we requested information about sociodemographic characteristics (i.e., age, ethnicity, relationship status) and sexual history (i.e., number of lifetime oral and vaginal sex partners).

Next, we assessed the prevalence of hookups. To avoid problems inherent in prior research (noted earlier), we did not use the term "hookup." Instead, we asked about specific sexual behaviors with a casual partner, defined as "someone whom you were not dating or in a romantic relationship with and, at the time of the sexual interaction, you had no mutual expectation of a romantic commitment." Women indicated with how many casual partners they had engaged in: (a) kissing, (b) had breasts touched, (c) touching partner's genitals or having your genitals touched outside of and (d) underneath of clothing/underwear, (e) oral sex, (f)

\footnotetext{
${ }^{1}$ In this initial study, we focus on college women because they appear more vulnerable than men to the possible consequences of hookups such as negative emotional reactions (Owen et al., in press), unwanted sexual activity (Larimer, Lydum, Anderson, \& Turner, 1999), sexually transmitted diseases (STDs; Institute of Medicine, 1997), and unintended pregnancy.
} 
vaginal sex, and (g) anal sex, before arriving on campus (T1) and since arriving on campus (T2).

Next, we assessed characteristics of hookups using 12 items that asked students about their most recent "hookup." In this section, we intentionally used the term "hookup" but we did not provide a definition; this required that women report on any experience that they considered a hookup. Here, they were asked: (a) when the hookup occurred, (b) with whom they hooked up (stranger, acquaintance, friend, ex-boyfriend, other), and (c) if it was the first time they hooked up with that partner. They were also asked (d) if they consumed alcohol or drugs before the hookup, and if so (e) how many drinks (using standard definitions; Dufour, 1999), and/or (f) what drug(s). Participants indicated (g) what specific sexual behaviors occurred, and whether a condom was used if (h) oral sex or (i) vaginal or anal sex occurred. They also indicated $(\mathrm{j})$ the reasons they hooked up from a list of 19 motives (adapted from Regan \& Dreyer, 1999; Weaver \& Herold, 2000). Lastly, they were asked to what extent they (k) enjoyed and/or (1) regretted their most recent hookup, on separate 7-point Likert scales. For all questions, women had the option to indicate that they had never hooked up.

To assess romantic interactions, women responded to 10 items about their most recent physical interaction with a "committed romantic relationship partner." Similar to the hookup items, women were asked (a) when the interaction occurred, (b) if they consumed alcohol or used any drugs beforehand, and if so (c) how many drinks and/or (d) what drug(s). Participants indicated (e) what specific sexual activities occurred and whether a condom was used if (f) oral sex or (g) vaginal or anal sex occurred. They also indicated $(\mathrm{h})$ the reasons they engaged in the romantic interaction from a list of 16 motives (adapted from Regan \& Dreyer, 1999; Weaver \& Herold, 2000). Lastly, they were asked to what extent they (i) enjoyed and/or (j) regretted the interaction, on separate 7-point Likert scales. For all questions, women had the option to indicate that they had not engaged in physical interaction with a romantic relationship partner.

\section{Results \\ Prevalence}

Table 1 displays the prevalence rates of seven sexual hookup behaviors as well as the mean (and median) number of hookup partners for three time intervals: (a) before college (T1), (b) during the first semester of college, and (c) lifetime (T2). Regarding specific sexual behaviors, by the end of the first semester in college $56 \%$ reported oral sex during a hookup in their lifetime, $42 \%$ reported vaginal sex, and $5 \%$ reported anal sex. As indicated in Table 1, McNemar's test for dependent proportions indicated that the lifetime prevalence of sexual touching, oral sex, and vaginal sex increased from T1 to T2 $(p s<.01)$. Separate analyses (not tabled) indicated that at least one type of penetrative sex (oral, vaginal, or anal sex) during a hookup was reported by $51 \%$ prior to college, $36 \%$ during their first semester, and $60 \%$ by the end of their first semester.

\section{Hookup Characteristics}

Across all participants and both survey occasions, 146 unique hookup events were described (the number of hookups exceeds the number of participants because some women reported unique events at T1 and T2). Most of these hookup events $(n=112 ; 77 \%)$ occurred since students arrived on campus.

Partners-Hookup partners included friends (47\%), acquaintances (23\%), strangers (14\%), ex-boyfriends (12\%), and others (4\%). Forty-four percent reported that their most recent hookup was not the first time they had hooked up with that particular partner. 
Motives-The most common motive for hooking up was sexual desire (80\%). Other frequently-endorsed motives were spontaneous urge (58\%), partner's attractiveness (56\%), intoxication (51\%), partner's willingness (33\%), and to feel attractive/desirable (29\%).

Alcohol and drug use-Participants reported consuming an average of 3.0 alcoholic drinks $(S D=3.0$, median $=3)$ prior to their hookup. Sixty-four percent consumed at least one alcoholic drink, and $7 \%$ used marijuana prior to their most recent hookups.

Sexual behavior-Almost all hookups (98\%) involved kissing, and many involved touching of the breasts (67\%) and genital touching outside (56\%) or underneath (46\%) clothing. Only $27 \%$ of hookups involved oral sex, $27 \%$ involved vaginal sex, and none involved anal sex. Condom use was reported for $0 \%$ of oral sex hookups and $69 \%$ of vaginal sex hookups.

Emotional consequences-Participants enjoyed their most recent hookups $(M=4.9$ on a 7-point scale, $S D=1.8)$ and indicated a low level of regret $(M=3.0, S D=2.2)$.

\section{Romantic Interactions}

Across all participants and both survey occasions, 158 unique romantic events were described (the number of events exceeds the number of participants because some women reported unique events at T1 and T2). Most of these events $(n=88 ; 56 \%)$ occurred since students arrived on campus.

Motives-Sexual desire (85\%) was the most common motive for romantic interactions. Other frequently endorsed motives were to show love for my partner (77\%), partner's attractiveness (65\%), my partner wanted to (40\%), and spontaneous urge (33\%).

Alcohol and drug use-Participants reported consuming an average of 0.5 ( $S D=1.4$, median $=0$ ) alcoholic drinks prior to their most recent romantic interactions. Sixteen percent consumed at least one alcoholic drink, and $4 \%$ used marijuana before the interaction. Sexual behavior. Nearly all romantic interactions (98\%) involved kissing, and many involved touching breasts $(81 \%)$ and genitals outside $(72 \%)$ or underneath (68\%) clothing; $44 \%$ involved oral sex, $56 \%$ involved vaginal sex, and $4 \%$ involved anal sex. Condom use was reported for $1 \%$ of oral sex, $75 \%$ of vaginal sex, and $44 \%$ of anal sex encounters.

Emotional consequences-On average, women reported a high degree of enjoyment $(M=5.8, S D=1.4)$ and little regret $(M=1.8, S D=1.5)$ of their most recent romantic interactions.

\section{Comparing Hookups and Romantic Interactions}

Hookups and romantic interactions were compared using data from the 99 participants who reported on both a hookup and a romantic event. (Percentages reported in this section refer to only these 99 participants.) To account for the non-independence of responses, paired samples $t$-tests were used for continuous variables, and McNemar's test for correlated proportions was used for dichotomous variables. We applied a Bonferroni correction to alpha of .05 due to the number of statistical tests (7), resulting in an alpha $(\alpha)$ of .007 .

Motives-Spontaneous urge (57\% vs. $34 \%$, McNemar's statistic $[1, N=99]=12.7, \mathrm{p}=$. $0004)$ and intoxication $(51 \%$ vs. $10 \%$, McNemar's statistic $[1, N=99]=38.1, \mathrm{p}<.0001)$ were endorsed more frequently as motives for hookups than for romantic interactions.

Alcohol and drug use-Alcohol use was more common prior to hookups than prior to romantic interactions. Women reported drinking prior to $63 \%$ of hookups, compared to only 
$21 \%$ of romantic interactions, McNemar's statistic $(1, N=99)=39.1, p<.0001$. Participants reported consuming more drinks prior to hookups $(M=3.1, S D=3.0$, median $=3)$ than prior to romantic interactions $(M=0.7, S D=1.5$, median $=0), t(98)=7.34, p<.0001, d=.74$. Marijuana use was infrequent and did not differ between romantic interactions $(4 \%)$ and hookups $(6 \%)$.

Sexual behavior-Touching breasts, touching genitals outside of clothing, touching genitals underneath clothing, oral sex, and vaginal sex occurred more often during romantic interactions than during hookups. Among both hookups and romantic interactions in which oral sex occurred, no participants reported condom use. During hookups in which vaginal sex occurred, $67 \%$ of participants reported using condoms, compared to $74 \%$ of participants using condoms during romantic interactions, McNemar's statistic $(1, N=26)=0.20, p=.65$.

Emotional consequences-Women reported enjoying their hookups $(M=5.0, S D=1.8)$ less than their most recent romantic interactions $(M=5.8, S D=1.4), t(98)=4.14, p<.0001$, $d=-.42$. They also reported regretting their most recent hookups $(M=3.0, S D=2.2)$ more than their most recent romantic interactions $(M=2.0, S D=1.7), t(98)=4.36, p<.0001, d=$. 44.

\section{Discussion}

This study advances knowledge regarding the behavioral epidemiology of hookups by (a) estimating the prevalence of specific behaviors in the hookup context and (b) providing more detailed information about the context and behavioral topography of hookups.

\section{Prevalence}

We assessed specific sexual behaviors in order to obtain precise hookup prevalence rates. By the end of their first semester of college, $60 \%$ of our sample had lifetime experience with oral, vaginal, or anal sex hookups, consistent with past research that assessed for oral and vaginal sex during hookups (Gute \& Eshbaugh, 2008; Penhollow et al., 2007). Knowing the percentage of late adolescents and young (emerging) adults who engage in penetrative sex during hookups affords a better understanding of the public health implications of the hookup culture. Many young people place themselves at risk for STDs by engaging in penetrative sex hookups with individuals who may have concurrent partners (Kelley, Borawski, Flocke, \& Keen, 2003).

\section{Hookup Characteristics}

Participants provided ample details regarding their experience before, during, and after hookups, and several key findings emerged. First, consistent with previous research that has found an association between alcohol use and hookup behavior (England, Shafer, \& Fogarty, 2007; Paul et al., 2000), the majority of hookups described by our participants were preceded by alcohol use. Intoxication may alter individuals' decision-making capability (i.e., shift the focus from inhibiting cues to more salient cues, such as sexual arousal; Steele \& Josephs, 1990) and lower their inhibitions; in addition, alcohol use may provide an "excuse" for proscribed behavior or the "liquid courage" needed to engage in such behavior (Stoner, George, Peters, \& Norris, 2007). The association between alcohol use and hooking up increases the risk for sexual victimization during these encounters (Abbey, 2002; Flack et al., 2007). College health providers can educate college students on the connection between alcohol use and hooking up and offer suggestions for monitoring alcohol use (Sugarman \& Carey, 2007).

Second, most women hooked up with someone they knew well, such as a friend or exboyfriend. Thus, conceptualizing a hookup as an interaction between strangers or brief acquaintances may miss many hookups. That friends are the most common hookup partners 
corroborates prior research revealing that sexual activity between friends is common ("friends with benefits"; Bisson \& Levine, 2009). Moreover, these findings raise the question of whether "friends with benefits" is a subtype of hookup or is a distinct type of relationship. Also, that $44 \%$ of participants had previously hooked up with their most recent hookup partner corroborates past findings (England et al., 2007); therefore, conceptualizing hookups as "onenight stands" is inaccurate and misleading. These data indicate that researchers should adopt a more ecologically valid understanding of hookups that does not restrict the relationship of hookup partners to strangers or brief acquaintances and does not limit their interaction to "onenight stands."

Third, students use the term hookup to refer to a wide range of behaviors. Nearly all of participants' most recent hookups involved kissing, but only $27 \%$ of hookups involved oral and/or vaginal sex. Thus, $73 \%$ did not involve vaginal sex, yet participants still referred to them as hookups; these results illustrate the variability in students' use of the term "hookup" (cf. England et al., 2007). Using the term hookup in research is problematic if some believe it to mean having vaginal sex but others believe it to be any intimate behavior (e.g., kissing).

Accordingly, researchers need to use specific behaviors when asking about hookup experiences (cf. Penhollow et al., 2007), in order to increase the likelihood that all participants understand the questions in the same way.

Finally, and perhaps most important from a health perspective, condoms were not used during any of the participants' most recent oral sex hookups. The lack of condom use during participants' oral sex hookups confirms previous research showing extremely low condom use rates for oral sex (Stone, Hatherall, Ingham, \& McEachran, 2006). Although oral sex is less risky than vaginal sex (Institute of Medicine, 1997), STDs can be transmitted through oral sex (Edwards \& Carne, 1998a, 1998b). In addition, condoms were not used in 31\% of participants' most recent vaginal sex hookups. Given that more than 9 million new cases of STDs occur each year among 15- to 24-year-old Americans (Weinstock, Berman, \& Cates, 2004), the high prevalence of unprotected oral and vaginal sex is a public health concern. These findings suggest a need for continued efforts to promote condom use among sexually active young people.

The comparison of romantic interactions with hookups also yielded several interesting findings. First, participants reported consuming alcohol more often and in greater amounts prior to hookups than prior to romantic interactions. Intoxication was reported as a motive for $51 \%$ of hookups, but just $10 \%$ of romantic interactions. These data reveal that alcohol plays a pivotal role in the hookup culture, not simply in general sexual activity among college students.

Second, hookups were less likely than romantic interactions to involve touching of the breasts and genitals, oral sex, and vaginal sex. This pattern might be expected given that hookup partners are not involved in any kind of committed relationship and may therefore be less likely to assume that such behaviors are appropriate or welcome by their partner.

Third, women reported enjoying romantic interactions more, and regretting them less, than hookups. The preference for sexual interaction with a romantic partner over a hookup partner may stem from physical or psychological reasons. For example, a long-term partner may be more likely than a new hookup partner to be able to please them sexually; indeed, women are more likely to report orgasms from romantic interactions than hookups (England et al., 2007). Enjoyment and regret of the interactions may also be affected by psychological processes. For instance, perhaps females enjoy romantic interactions more than hookups because they do not have to worry about pejorative labels or developing a negative reputation (Bogle, 2008). 


\section{Limitations and Future Directions}

The limitations of this research should be acknowledged. First, our sample of primarily heterosexual Caucasian females may limit the generalizability of the results. We focused on females because of their greater risk for negative consequences of hookups, but future research should sample males; ethnic minority students; and gay, lesbian, and bisexual students. Members of fraternities and sororities may be of particular interest because they tend to have more sexual partners and to have sex under the influence of alcohol or drugs more often than independent (non-fraternity- or sorority-affiliated) students (cf. Scott-Sheldon, Carey, \& Carey, 2008).

A second limitation of the study is its atheoretical nature. We developed our research questions after a review of the empirical literature on hooking up; we attempted to fill in gaps in the knowledge base and resolve inconsistencies or debatable points. Future research, guided by psychosocial theory, can extend the results of this empirical investigation.

Third, the prevalence estimates we obtained reflect the assessment methods we used. The ambiguity inherent in the term hookup makes it difficult to assess its prevalence. However, the methods we employed enabled a more accurate measurement of hookup prevalence relative to prior studies. Moreover, in our assessment of hookup characteristics, we asked participants to self-label hookups so we did not limit our study to only those situations that we understood to be hookups.

Fourth, the study design does not permit causal inferences or exploration of the health consequences of hooking up. Longitudinal research might examine physical and mental health consequences of hooking up (cf. Fielder \& Carey, in press) and whether hookups influence relationship satisfaction and sexual health. Moreover, the prevalence of hooking up suggests that it confers benefits to young people so research could examine whether positive outcomes accrue from this behavior (e.g., increased sexual awareness or feelings of attractiveness, increased social connectedness, opportunity to acquire sexual experience, and greater perceived independence).

These results suggest that a majority of female students engage in sexual hookups during high school and their first semester of college. Thus, recent reports describing a new hookup culture among students may be accurate. Although the behaviors occurring within the hookup context are not new, the extent to which hookups have become a normative way for young people to interact, particularly during college and with friends (who are not romantic partners), is noteworthy (Bogle, 2007; Garcia \& Reiber, 2008). This study increases understanding of the hookup experience with regard to partner types, alcohol use, sexual behaviors, condom use, and emotional reactions. The defining characteristic of a hookup seems to be the lack of mutually understood romantic commitment rather than a particular relationship or pattern of interaction. Less clear, and worthy of research, are the implications of hookups for health. Research exploring these outcomes is needed before we can draw conclusions about the effects of this increasingly prevalent sexual behavior pattern.

\section{Acknowledgments}

This research was supported by grants from Psi Chi, the National Honor Society in Psychology, and from the National Institute of Mental Health (R01-MH068171). The authors would like to thank Hillary L. Bishop for her help with data collection and data entry.

\section{References}

Abbey A. Alcohol-related sexual assault: A common problem among college students. Journal of Studies on Alcohol 2002;Suppl 14:118-128. 
Bisson MA, Levine TR. Negotiating a friends with benefits relationship. Archives of Sexual Behavior 2009;38:66-73. [PubMed: 17851750]

Bogle KA. The shift from dating to hooking up in college: What scholars have missed. Sociology Compass 2007;1(2):775-788.

Bogle, KA. Hooking up: Sex, dating, and relationships on campus. New York: New York University Press; 2008.

Dufour MC. What is moderate drinking: Defining “drinks" and drinking. Alcohol Research and Health 1999;23:5-14. [PubMed: 10890793]

Edwards S, Carne C. Oral sex and the transmission of non-viral STIs. Sexually Transmitted Infections 1998a;74:95-100. [PubMed: 9634339]

Edwards S, Carne C. Oral sex and the transmission of viral STIs. Sexually Transmitted Infections 1998b; 74:6-10. [PubMed: 9634307]

England, P.; Shafer, EF.; Fogarty, ACK. Hooking up and forming romantic relationships on today's college campuses. In: Kimmel, MS.; Aronson, A., editors. The Gendered Society Reader. New York: Oxford University Press; 2007. p. 531-547.

Eshbaugh EM, Gute G. Hookups and sexual regret among college women. Journal of Social Psychology 2008;148:77-89. [PubMed: 18476484]

Fielder RL, Carey MP. Predictors and consequences of sexual "hookups" among college students: A short-term prospective study. Archives of Sexual Behavior. (in press).

Flack WF, Daubman KA, Caron ML, Asadorian JA, D'Aureli NR, Gigliotti SN, et al. Risk factors and consequences of unwanted sex among university students: Hooking up, alcohol, and stress response. Journal of Interpersonal Violence 2007;22:139-157. [PubMed: 17202573]

Garcia JR, Reiber C. Hook-up behavior: A biopsychosocial perspective. Journal of Social, Evolutionary, and Cultural Psychology 2008;2:192-208.

Gute G, Eshbaugh EM. Personality as a predictor of hooking up among college students. Journal of Community Health Nursing 2008;25:26-43. [PubMed: 18444064]

Institute of Medicine. Factors that contribute to the hidden epidemic. In: Eng, TR.; Butler, WT., editors. The hidden epidemic: Confronting sexually transmitted diseases. Washington, DC: National Academy Press; 1997. p. 69-177.

Kelley SS, Borawski EA, Flocke SA, Keen KJ. The role of sequential and concurrent sexual relationships in the risk of sexually transmitted diseases among adolescents. Journal of Adolescent Health 2003;32:296-305. [PubMed: 12667734]

Lambert TA, Kahn AS, Apple KJ. Pluralistic ignorance and hooking up. Journal of Sex Research 2003;40:129-133. [PubMed: 12908120]

Larimer ME, Lydum AR, Anderson BK, Turner AP. Male and female recipients of unwanted sexual contact in a college student sample: Prevalence rates, alcohol use, and depression symptoms. Sex Roles 1999;40:295-308.

Owen JJ, Rhoades GK, Stanley SM, Fincham FD. "Hooking up" among college students: Demographic and psychosocial correlates. Archives of Sexual Behavior. (in press).

Paul EL, Hayes KA. The causalities of "casual" sex: A qualitative exploration of the phenomenology of college students' hookups. Journal of Social and Personal Relationships 2002;19:639-661.

Paul EL, McManus B, Hayes A. "Hookups": Characteristics and correlates of college students' spontaneous and anonymous sexual experiences. Journal of Sex Research 2000;37:76-88.

Penhollow T, Young M, Bailey W. Relationship between religiosity and "hooking up" behavior. American Journal of Health Education 2007;38:338-345.

Regan PC, Dreyer CS. Lust? Love? Status? Young adults' motives for engaging in casual sex. Journal of Psychology and Human Sexuality 1999;11:1-24.

Scott-Sheldon LAJ, Carey KB, Carey MP. Health behavior and college students: Does Greek affiliation matter? Journal of Behavioral Medicine 2008;31:61-70. [PubMed: 17999173]

Steele CM, Josephs RA. Alcohol myopia: Its prized and dangerous effects. American Psychologist 1990;45:921-933. [PubMed: 2221564]

Stepp, LS. Unhooked: How young women pursue sex, delay love, and lose at both. New York: Riverhead Books; 2007. 
Stone N, Hatherall B, Ingham R, McEachran J. Oral sex and condom use among young people in the United Kingdom. Perspectives on Sexual and Reproductive Health 2006;38:6-12. [PubMed: 16554266]

Stoner SA, George WH, Peters LM, Norris J. Liquid courage: Alcohol fosters risky sexual decisionmaking in individuals with sexual fears. AIDS and Behavior 2007;11:227-237. [PubMed: 16802196]

Sugarman DE, Carey KB. The relationship between drinking control strategies and college student alcohol use. Psychology of Addictive Behaviors 2007;21:338-345. [PubMed: 17874884]

Weaver SJ, Herold ES. Casual sex and women: Measurement and motivational issues. Journal of Psychology and Human Sexuality 2000;12:23-41.

Weinhardt LS, Carey MP. Does alcohol lead to sexual risk behavior? Findings from event-level research. Annual Review of Sex Research 2000;11:125-57.

Weinstock H, Berman S, Cates W. Sexually transmitted diseases among American youth: Incidence and prevalence estimates, 2000. Perspectives on Sexual and Reproductive Health 2004;36:6-10.

[PubMed: 14982671] 

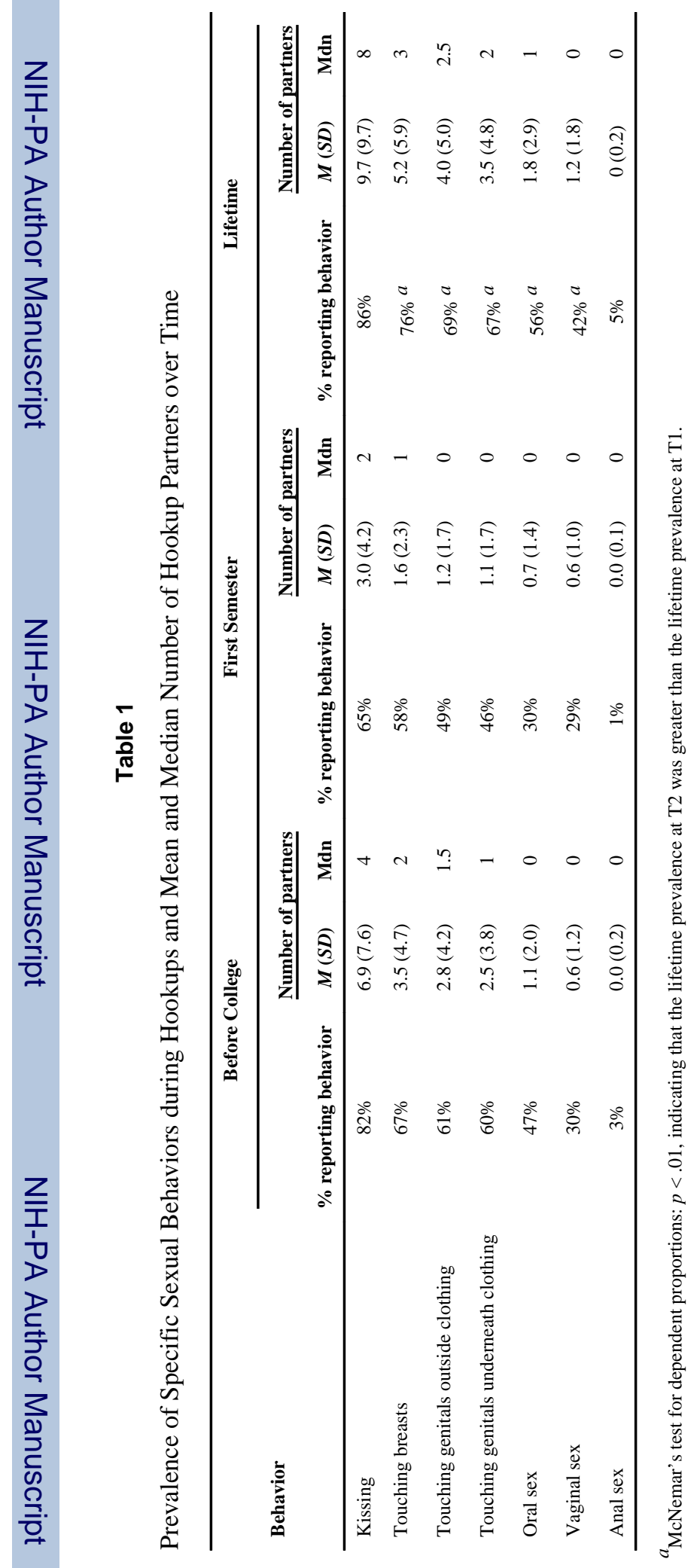

J Sex Marital Ther. Author manuscript; available in PMC 2011 January 1. 